\title{
Tracheobronchial stent sizing and deployment practices airway stenting practices around the world: a survey study
}

\author{
Roshen Mathew ${ }^{1}$, Kedar Hibare ${ }^{2}$, Levent Dalar ${ }^{3}$, Winnie Elma Roy ${ }^{4}$ \\ ${ }^{1}$ Department of Internal Medicine, UAB School of Medicine (Huntsville Hospital), Huntsville, AL, USA; ${ }^{2}$ Department of Interventional \\ Pulmonology, Narayana Health, Bangalore, India; ${ }^{3}$ Department of Pulmonary Medicine, School of Medicine, Istanbul Bilim University, Istanbul, \\ Turkey; ${ }^{4} \mathrm{UAB}$ School of Public Health, Birmingham, AL, USA \\ Contributions: (I) Conception and design: R Mathew, K Hibare, L Dalar; (II) Administrative support: WE Roy; (III) Provision of study materials or \\ patients: All authors; (IV) Collection and assembly of data: All authors; (V) Data analysis and interpretation: R Mathew, WE Roy; (VI) Manuscript \\ writing: All authors; (VII) Final approval of manuscript: All authors. \\ Correspondence to: Roshen Mathew, MD. Clinical Assistant Professor, 206 East 4th St., Williamstown, WV 26187, USA. \\ Email: Mathew.roshen@gmail.com.
}

Background: Tracheobronchial stents types, uses, techniques for deployment and extraction have practice variations around the world.

Methods: We collected responses by sending an online survey of 8 questions to world interventional bronchology member societies and social media groups.

Results: There were 269 respondents from 47 countries. Europe had 97 respondents from 22 countries. There were 8 respondents from Australia, 7 from Africa (3 countries) and 7 from 4 countries in South America (SA). North America (NA) had 72 respondents from 3 countries. Asia had 78 respondents from 14 countries. For stent placements 15\% [41] used fiberoptic bronchoscope (FB) only. Rigid bronchoscopy (RB) was solely utilized by $38 \%$ [102]. Forty-six percent [123] used a combination of RB and FB (P value $<0.00001$ ). For stent extraction 13\% [19] used FB alone, 57\% [85] used RB, and 36\% [54] used a combination of RB and FB (P value <0.00001). Placement of stents were 50.5\% [135] only by direct visualization. Twentythree percent [61] always used fluoroscopic guidance. Twenty-six-point-five percent [71] used fluoroscopy in certain cases ( $\mathrm{P}$ value $<0.00001$ ). Sixty percent [162] decided stent sizing by measurements of stenotic and non-stenotic areas on radiology. Twelve percent [32] respondents used sizing devices. Sixty-five percent [177] used a ruler and bronchoscope to measure stenotic areas. Thirty-eight percent [104] used visual estimation and experience. Seven percent [19] used serial balloon dilatation size. To prevent clogging of stents, 22\% [59] prescribed mucolytics. Seventy-three percent [195] nebulized saline, 26\% [70] had Mucomyst Nebulization, 24\% [65] Nebulized bronchodilators and other methods 11\% [30] were advised. Covered self-expandable metal stents (SEMS) 44\% was the commonest type of stent used around the world. Silicone stents 37\%, Y stents 15\%, uncovered SEMS 12\%, Montgomery T tube 5\% followed. Polyflex stents 3\% and custommade stents $3 \%$ were least used. Biodegradable stents were used by $7.5 \%$, and not used by $92.5 \%$.

Conclusions: Tracheobronchial stent practice norms have slowly evolved, but its practice variations lack uniformity, and have sparse evidence-based studies for its direction.

Keywords: Tracheobronchial stents; interventional pulmonology; biodegradable stents; rigid bronchoscopy; fluoroscopy

Submitted May 31, 2020. Accepted for publication Sep 07, 2020.

doi: $10.21037 /$ jtd-20-2080

View this article at: http://dx.doi.org/10.21037/jtd-20-2080

(C) Journal of Thoracic Disease. All rights reserved. 


\section{Introduction}

Tracheobronchial stents have been valuable adjuncts to the palliation of patients presenting with central airway obstruction (CAO). It also has been used as a bridge prior to final therapeutic intervention in many kinds of benign airway stenosis, malacia and in post-transplant scenarios to manage airway dehiscence. Advances in material science, technology and designing have changed a stent from being bare metallic mesh or a silicone tube, to being biodegradable and or custom made specifically for an individual patient with help of various three-dimensional (3D) printing technologies.

Over the last 3 decades of stent use in the tracheobronchial tree, various techniques for sizing stents before deployment, insertion and extraction exist with practice variations from around the world. In talking to colleagues from different countries in world interventional conferences we clearly see varied norms of practices and preferences in use of tracheobronchial stents. The extent of stent practices and its varied use around the world is not known clearly. A study somewhat in this regard was done by the European Association of Bronchology and Interventional Pulmonology (EABIP) which did provide a bird's eye view on stent use and deployment practices in Europe. The purpose of this study is to concisely try to capture and summarize these varied practices from around the world. We present the following article in accordance with the STROBE reporting checklist (available at http://dx.doi. org/10.21037/jtd-20-2080).

\section{Methods}

This was an observational cross-sectional study with a descriptive focus to understand practice variations without any interventions. We collected data by sending an online survey using an online data collection service (Survey Monkey). Emails were sent to practicing interventional pulmonary practitioners, thoracic surgeons and members of interventional bronchology member societies around the world. Additionally, links were also posted in social media society groups such as the Interventional Pneumologie and Global Society of Interventional Pulmonology on social media of Facebook to get some of our responses. This was done over a period of 6 months ending in first few months of 2019. This was followed by compilation of the data to get the inferences towards the mid of 2019. The following questions as below were asked for the survey:
(I) In which country do you work or practice?

(II) How do you size your tracheal and bronchial airway stents?

(III) How do you place your airway stents most of the time?

(IV) Do you always use fluoroscopic guidance for placement of your airway stents?

(V) What advice do you give to your patients to prevent mucus clogging of their stents?

(VI) What is approximately the percentage for choices of tracheobronchial stents in your practice?

(VII) Do you have any experience with biodegradable stents? If Yes, please comment on what cases you have used.

(VIII) How do you remove tracheobronchial stents you have placed?

With widespread email requests send to members of multiple interventional pulmonary and thoracic societies, we tried to get a fair representation from countries around the world. Few duplicates of individual responses were noted on data analysis in the database. This was excluded from the count of the responses of the study for a more accurate representation. Efforts were made individually to contact the respondents for clarifications and missing data if required during the study. The missing data of individual questions is reported and included with the supplement of this manuscript for the readers.

\section{Statistical analysis}

Using statistical software SPSS 20 (Statistical Package for the Social Sciences), continuous parameters are presented by means. Categorical variables are reported as frequencies and percentages. This was done separately for each of the continents. Chi square contingency tables for variables were examined to get $\mathrm{P}$ values for practice preferences overall for the study. The $\mathrm{P}$ values were calculated and checked for significance for a value of $\mathrm{P}<0.05$.

\section{Results}

We had a total of 269 responses from 47 countries to the survey. One hundred and twenty-four responses were from 644 emails (19\% email response rate) sent to various physicians performing tracheobronchial stents in their practice. One hundred and twenty-three responses were from web links sent to multiple members in regional interventional bronchology societies around the world. 
Tracheobronchial stents: Norms \& practices

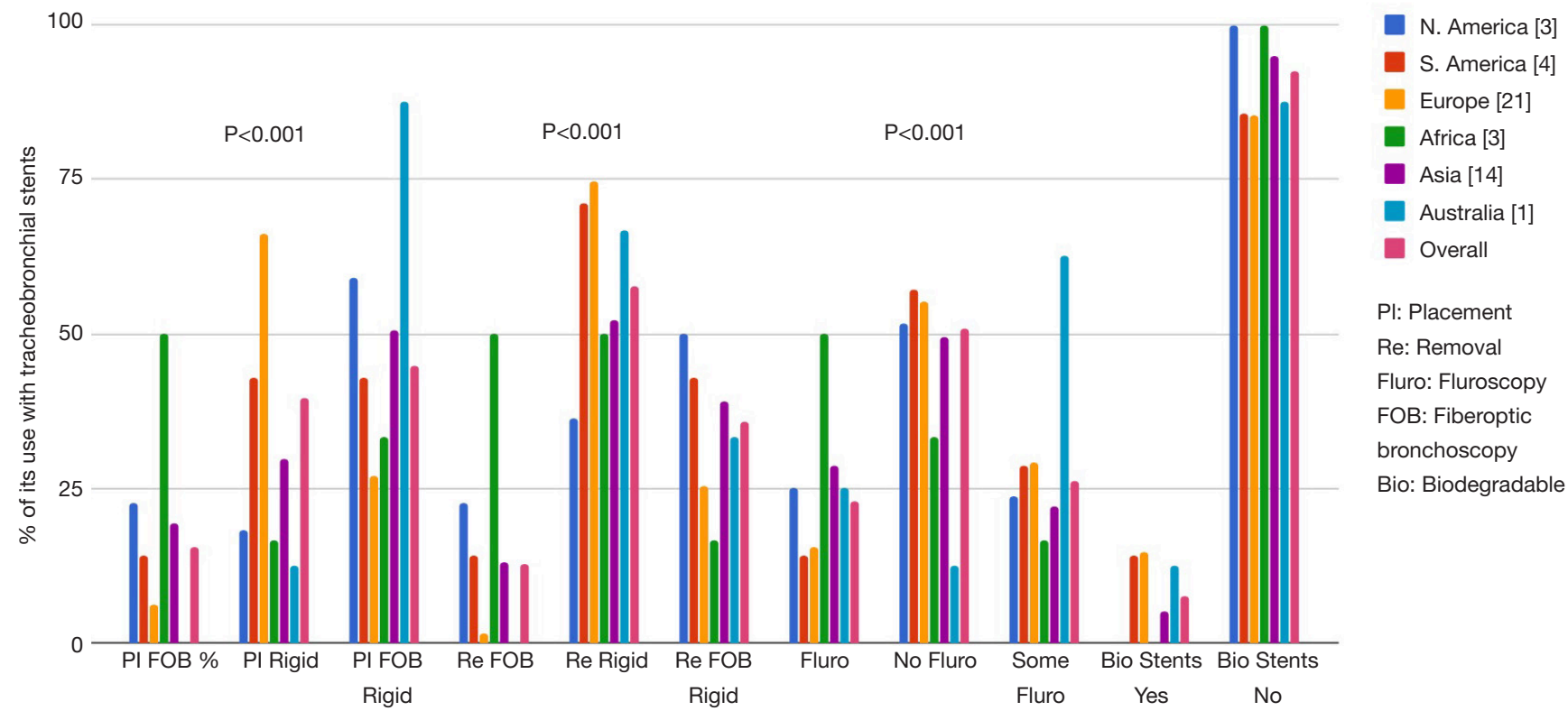

Figure 1 Tracheobronchial stents Norms \& Practices breakdown by continents. Pl FOB: placement with fiberoptic bronchoscopy; Pl Rigid: placement with rigid bronchoscopy; Pl FOB Rigid: placement with a combination of FOB and rigid bronchoscopy; Re FOB: removal by fiberoptic bronchoscopy; Re Rigid: removal by rigid bronchoscopy; Re FOB Rigid: removal by combination of FOB and rigid bronchoscopy; Fluro: use of fluoroscopy for stent placement; No Fluro: no use of fluoroscopy for stent placement; Some Fluro: use of Fluoroscopy in selected cases of stent placement; BioStents Yes: have experience with biodegradable stents; BioStents No: no experience with biodegradable stents.

From social media posts only 22 responses $(8 \%)$ were obtained. From the respondents of the survey $17 \%$ were thoracic surgeons, $82 \%$ were pulmonologists doing stent interventions in practice and $1 \%$ were interventional radiologists doing some airway stents occasionally. The average time taken by respondents who completed our survey answering all the questions was 3.25 minutes for 8 questions.

In our survey Europe had the most responses, 97 respondents from 22 European countries. The lower number of respondents were 8 respondents from Australia itself, 7 respondents from 3 countries of Africa, and 7 respondents from 4 countries of South America (SA) respectively. North America (NA) had 72 respondents from 3 countries and Asia had 78 respondents from 14 countries. A detailed response on the breakdown of respondents from each continent and country are included as part of the supplement of this manuscript.

For the placement of tracheobronchial stents $15 \%$ [41] used fiberoptic bronchoscope (FB) only. Rigid bronchoscopy (RB) was only utilized by $38 \%$ [102] of the respondents, and $46 \%$ [123] used a combination of rigid and flexible bronchoscopy for placements of stents.

Regarding fluoroscopic guidance for the placement of stents $50.5 \%$ [135] placed the stents only by direct visualization during the procedure. Twenty-three percent [61] always used fluoroscopic guidance for placement of the stents and 26.5\% [71] used them sometimes in certain cases.

Fluoroscopy for stent placements is least used SA and Europe at $15 \%$.

For extraction of tracheobronchial stents, 13\% [19] took them out by using FB alone. Fifty-seven percent [85] did stent removal by RB procedure only. Thirtysix percent [54] used a combination of $\mathrm{RB}$ and $\mathrm{FB}$ for their extractions. In Europe, the extraction of stents was mostly done by the RB over 73\% [44] of the time, or by a combination of $\mathrm{RB}$ and $\mathrm{FB} 27 \%$ [16] of the time. There was negligible use about $1.6 \%$ using $\mathrm{FB}$ for stent extractions in Europe. The norms and practices for stent placements and extractions around the world found in the survey are depicted in a graph as Figure 1. In this survey the $\mathrm{P}$ value was $<0.00001$ for increased 
Table 1 Advice by respondents to patients to prevent stent clogging with mucus

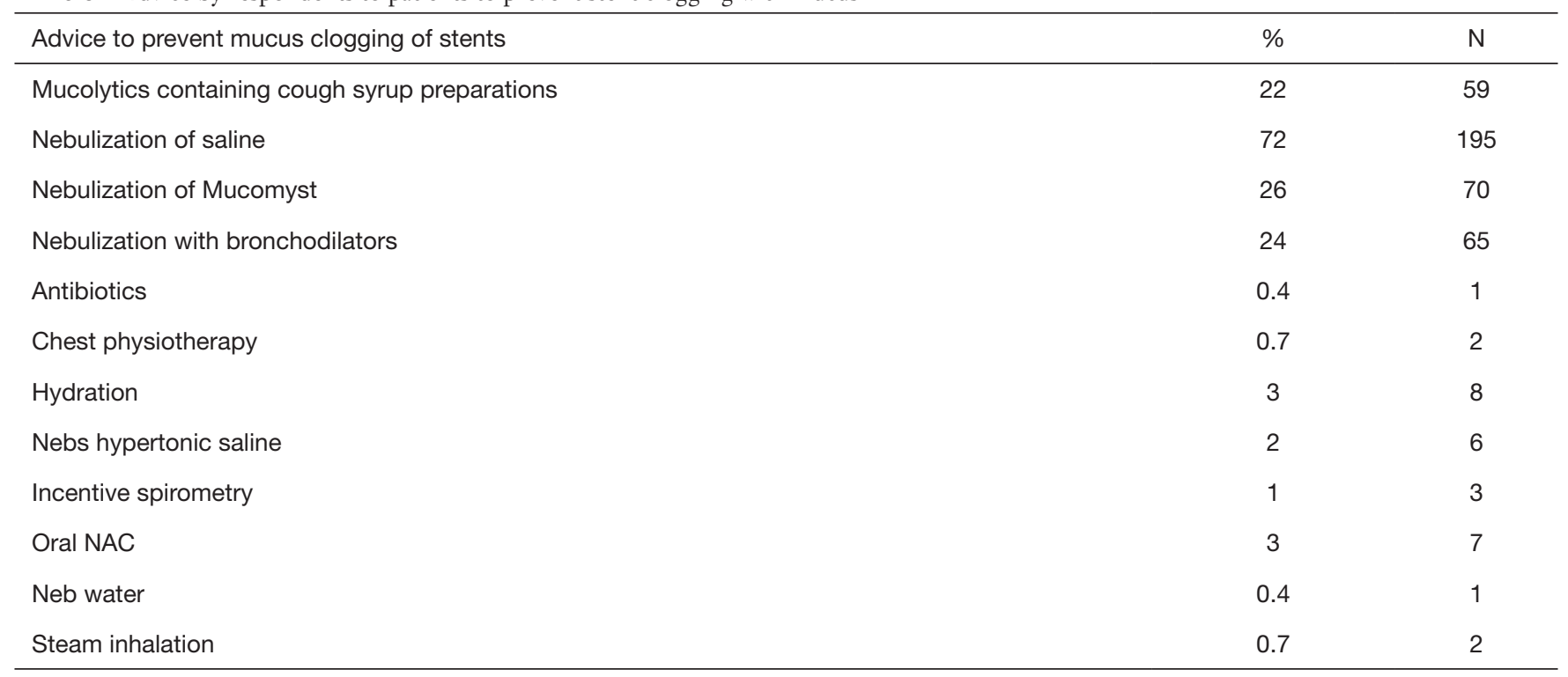

NAC, N-acetylcysteine.

popularity of the RB use in placement and removal of stents. $\mathrm{P}$ value was also significant $<0.00001$ for not using fluoroscopy during stent placements.

To ascertain accurate sizing of stents before placement, there were many techniques employed. It goes on from a spectrum with approximate sizing by visual estimation and experience, to the use of measuring devices designed for this purpose. Of the respondents $60 \%$ [162] decided on stent sizing by gauging measurements of stenotic and non-stenotic areas on radiology images. Twelve percent [32] respondents used sizing devices like an Aerosizer (manufacturer: MERIT) to get the approximate size of the stents to be placed. Sixty-five percent [177] used a ruler and bronchoscope to measure the length of stenotic areas during the procedure to size their stents. Thirty-eight percent [104] used a visual estimation by experience after assessing the stenotic areas of interest during the procedure for sizing of the stents required. In the African subcontinent, using the ruler and the bronchoscope was the most preferred way $(43 \%)$ to determine sizes required for stents. Few other methods were also found to be in practice adding up to $7 \%$ [19]. Of these modalities, number of respondents using serial balloon dilatation size by controlled radial expansion (CRE) balloon [10], size of the largest rigid bronchoscope [4], radial endobronchial ultrasound (EBUS) [2], rigid forceps size [2] and stereo bronchoscope [1].

To prevent clogging of stents by mucus there were varied practices too. Twenty-two percent [59] prescribed mucolytic containing expectorant cough syrups. Seventy-three percent [195] used nebulized normal saline to keep stent surfaces clean. $\mathrm{N}$-acetylcysteine nebulizations were advised to patients by $26 \%$ [70]. Nebulized bronchodilators used daily were advised by $24 \%$ [65]. Other methods were also noted additionally from the survey $11 \%$ [30] are summarized in Table 1.

The commonest type of stent being used around the world was the covered self-expandable metal stents (SEMS). Covered SEMS mean use was $(44 \%)$, followed by the silicone stents (37\%), Y stents (15\%), uncovered SEMS (12\%), Montgomery $\mathrm{T}$ tube (5\%). The least used stents were the Polyflex stents mean overall use $(3 \%)$ and the custom-made stents (3\%).

Covered SEMS were used by $92 \%$ of the respondents with a mean use of $44 \%$ around the world. It was least used $34-35 \%$ in SA and Europe. Silicone stents excluding the Y stents, were used by $88 \%$ of the respondents. It was the second most popular stent in use with a mean use of $37 \%$. It was most used in Europe and in SA with a mean of $47 \%$ and $40 \%$ respectively. It was least used in NA and Australia about $40-47 \%$. Y stents were being used by $78 \%$ of the respondents, but with only a mean of $15 \%$ use around the world. It was used average $14-17 \%$ in various regions of the world and was least used in Africa. The uncovered SEMS were being used by $72 \%$ of respondents with a mean use of $12 \%$. It was least used $9 \%$ in NA and Europe, most used in SA 25\% and Africa 35\%. Custom made stents were used by 
Table 2 Percentage uses breakdown by continents for different types of stents

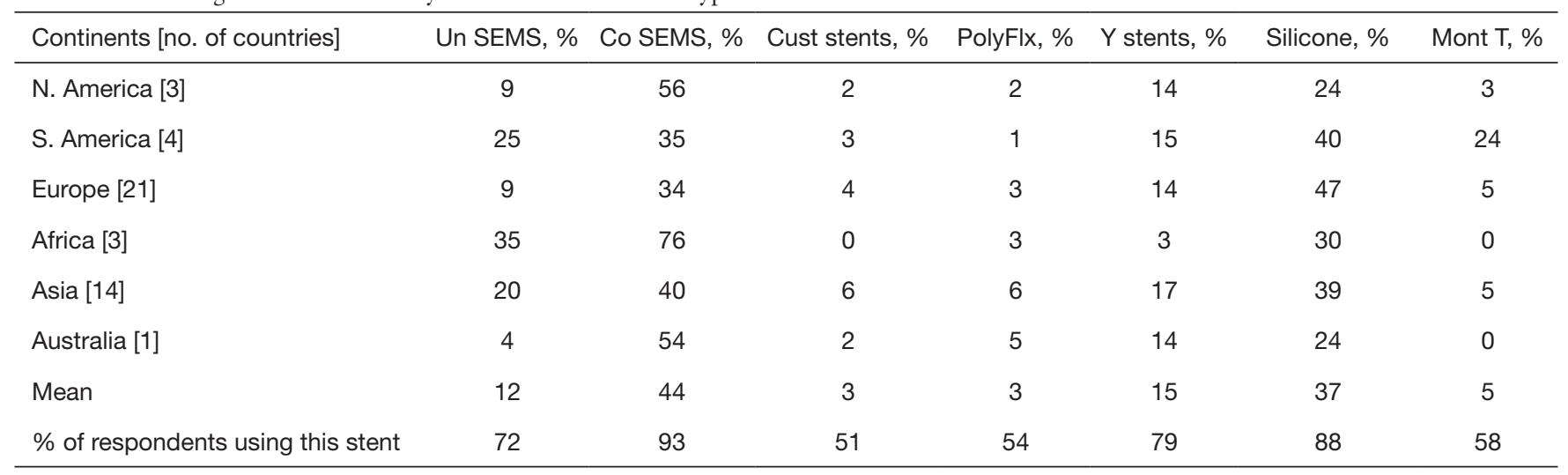

Un SEMS: uncovered self-expandable metallic stent; Co SEMS: covered self-expandable metallic stent; Cust stents: custom stents; PolyFlx: Polyflex stents; Silicone: silicone stents excluding Y stents; Y stents: Y-shaped silicone stents; Mont T: Montgomery T tubes.

Table 3 Respondents with experience using biodegradable stents

\begin{tabular}{lcc}
\hline Respondents & $\%$ & No. of responses \\
\hline Have experience: yes & 7.5 & 20 \\
Experience on: & 10 & 2 \\
Animal model & 25 & 5 \\
Benign stenosis & 10 & 2 \\
Observed/assist & 10 & 2 \\
Post lung transplant & 5 & 1 \\
Postop stenosis & 10 & 2 \\
Tracheomalacia & 5 & 1 \\
Training course & - & 2 \\
Skipped answering question & 92.5 & 247 \\
No experience & & \\
\hline
\end{tabular}

about $51 \%$ of the respondents with a mean use of only $3 \%$. A breakdown of this data by continents is also summarized in Table 2.

Biodegradable stent use is a relatively novel idea around the world. Ninety-two-point five percent [247] of the respondents did not have any experience with it, while $7.5 \%$ [20] of the respondents did have some experience using it for various conditions. Conditions where the respondents had experience with it is summarized as in Table 3. $\mathrm{P}$ value was also significant $<0.00001$ in the limited use of biodegradable stents worldwide as per this survey.

Graphs and tables detailing these results discussed above and number of responses are included in the online supplement of this manuscript (Figures S1-S9 and Tables S1-S5).

\section{Discussion}

The practice of using stents to relieve airway obstruction has been around for 30 years starting back in 1987 with the development of a dedicated Dumon stent $(1,2)$. This was predominantly used in the central airways. There has been an evolution to the type of stents available now and the area of stenting over these 30 years. Stenting of peripheral and lobar airways is a viable option now (3-5). Custom made, and biodegradable stents made by various technologies including $3 \mathrm{D}$ printing also have started coming to the forefront in stent development these days (6).

In this survey-based study we have attempted to get a 
sense of the practice and use of tracheobronchial stents from around the world. A study trying to get some attributes in placement of stents, its cost effectiveness and economic viability was done recently in Europe in collaboration with the EABIP by Dutau et al. (2). Delegates of 26 countries in Europe performing tracheobronchial stents had responded to that survey.

For placement of stents overall around the world a combination of $\mathrm{RB}$ and $\mathrm{FB}$ technique $(46 \%)$ is the most preferred modality. RB is the most preferred technique in Europe alone (66\%) with almost all centers over 200 providing this service (2). The results from the EABIP study reiterates the practice patterns we saw with our survey of Europe. Training for RB is more readily available and possibly even a part of the curriculum for respiratory medicine trainees in Europe explaining its pronounced use (3). Our survey also showed that FB was used solely for placement of stents most prevalent in Africa (50\%). Is this because of the lack of RB training available in Africa? Or is this because of RB being a domain of thoracic surgery in most of the African countries? Our respondents from Africa were mostly pulmonologists. Because of the small data sample in the survey of Africa, there could be a selection bias in our data of the African continent. RB is a great tool for central airway stenosis interventions, but combined with the FB maneuverability, choice of tumor ablation modalities, and most importantly its reach into the upper lobes and peripheral airways makes it a complete duo for interventional airway procedures $(7,8)$.

Fluoroscopic guidance for placement of stents came along when interventional radiologists were the only ones placing them. In our pool of respondents about $0.5 \%$ were radiologists placing them. This practice involves radiation exposure to the patient and staff involved. It has no additional benefit, compared to direct bronchoscope visualization during placement (8). Fluoroscopy for stent placements was least used in SA and Europe. Direct visualization during procedures without fluoroscopy (50\%) was still the most preferred method of stent placement around the world. On subgroup analysis of the data it was found that the use of fluoroscopy for stent placements was more frequent during use of $\mathrm{FB}$ and reduced with the use of RB. This was a statistically significant result with $\mathrm{P}$ value $<0.00001$. It is not clear why in Africa and Australia there was more use of fluoroscopy. This observation rather than being truly factual is presumably the result of a participation bias and is undetermined from our survey.

There was one respondent from Japan using stereoscopic bronchoscopy for stent placement. Stereoscopic bronchoscopy is a new diagnostic instrument. It is the same as a standard bronchoscope, utilizes 2 lenses to measure the airway using the principles of triangulation. It has enhanced capability to determine the diameter and crosssectional area of the airway during intervention in realtime (9-11). Miyazawa et al. in 2004 had identified choke points in Central Airway Obstruction (CAO); utilizing spirometry, 3D CT scan and ultrathin bronchoscopy prior to using radial EBUS to identify the precise size of stent to be placed. It resulted in improved dyspnea scores and spirometry $(9,10)$. Nobuyama et al. from Japan (11) prospectively compared using preoperative stereoscopic and multidetector computed tomography (MD-CT) images to select the appropriate stent size for airway stenosis. It demonstrated accurate results in real time with stent sizing and choke point measurements with stereoscopic bronchoscopy compared to MD-CT.

For determination of sizing of stents required there was also much variability across the continents. Measuring the stenotic areas prior to procedure from imaging and measuring the stenotic area dimensions during bronchoscopy were the most popular methods in use. However, the norm of using visual estimation by experience of the operator was still very prevalent $(20-50 \%)$ across the continents. Visual estimation for stent sizing is however not used in Australia. Is this data for Australia a participation bias or just mere true factual finding is again unclear from our survey. A study of American Association of Bronchology and Interventional Pulmonology (AABIP) members (12) with 118 responses was done in 2015. It showed 91\% of its respondents used visual estimation to define the degree of $\mathrm{CAO}$, and to give a numeric description to the degree of CAO. It also showed 55 respondents who additionally used various techniques for grading CAO. Those respondents were also not very content with devices available for measuring the degree of CAO. This study also showed that $46 \%$ of its respondents agree there needs to be a standardized CAO measurement. Most utilized for $\mathrm{CAO}$ measurement was, imaging modalities with $3 \mathrm{D}$ reconstruction. Other methods used were airway sizing devices, RB size for measurement, use of a CRE balloons and spirometry in decreasing order respectively (12). Our survey did not particularly ask respondents on sizing of stent length versus width separately. However, this survey and the AABIP study reiterates the fact that stent sizing and $\mathrm{CAO}$ measurement is a very relevant area of the procedure that needs more standardization. 
The covered SEMS were very popular with our survey respondents. The popularity of the SEMS came into being since it was feasible to place it under conscious sedation and resulted in reasonable palliation of symptomatic CAO with minimal procedural complications (13). However, we did not try to collect data on popularity of manufacturer brands of SEMS being used in different countries. We feel ascertaining this information would not add much to the goal of this survey, besides just adding another question to the survey and possibly increasing attrition rate. From talking to delegates and respondents from international society meetings it was clear there were locally manufacturing vendors which helped significantly reduce cost of SEMS placement in certain countries.

Custom made stents experience were documented by about $51 \%$ of the respondents. This was an interesting disparity considering its mean overall use of $4 \%$. On further examining data, it was noted some of the custommade stent use was documented in countries where the technology to tailor custom stents were not available yet, and likely not economically viable. Hence to clarify this discord in data we further contacted respondents by email regarding customization practices for their stent use. It was apparent thus customization defined by some of the respondents were at site customization being done to the silicone stents, mostly by the operator prior to their deployment. This explains the familiarity in use with the number of respondents as denoted in the survey. The practice of stent customization has been documented by Breen and Dutau from their 2009 single center study (14). Further, customization practices at site have been subsequently adapted by others also (15). Custom made stents were being utilized for complex airway stenosis from various causes including post lung transplant (16). Custom stent production using $3 \mathrm{D}$ printing has proved to be useful in the development of personalized stents. $3 \mathrm{D}$ printing technology has recently been approved by the Food and Drug Administration (FDA) for customized printing of stents. It has been gaining some use in Europe (17) and is also thought to slowly start gaining momentum in NA after its FDA approval. Individual tailored stents are preferable over customizing purchased airway stents. The legal, practical, technical implications and challenges in creating individualized and customized stents have been extensively discussed by Freitag et al. (18).

Biodegradable stents represent an innovative invention in the future of stent technology and practices. Made of degradable polymers like polydioxanone these stents degrade without need for any extraction. In the largest study with biodegradable stent insertions in post-lung transplant patients involving 11 stent insertions by Fuehner, the median time for complete degradation was 141 days $(19,20)$. In our survey only 20 respondents $(7.5 \%)$ had some experience with the use of biodegradable stents. Fourteen out of the 20 respondents were from Europe, where the biodegradable stents use has been rapidly evolving in some selected centers (21). Most of their use as per the respondents was in benign stenosis $25 \%$, followed by some use in post lung transplant cases $10 \%$, tracheomalacia $10 \%$ and some in post-operative stenosis $5 \%$. The use of biodegradable stents in NA has not been approved by the FDA. Additionally, no product patents have been filed with the FDA by any stent manufactures in NA for its experimental or compassionate use. Thus, we believe biodegradable stents are a novel idea with a lot of its ongoing research work focused mainly in Europe.

Besides migration, mucus plugging is a frequent complication confronted after stent insertion. The main approach used to prevent plugging among participants of this survey was saline nebulization. Stent as a foreign body does not allow transportation of mucus with mucociliary inhibition and additionally can promote mucus production (22). Normal saline nebulization is the most cost effective, easily available approach to prevent mucus plugging. Hypertonic saline nebulization use was seen recommended by $6(2 \%)$ of the respondents. Besides anecdotal experiences, the use of hypertonic saline vs normal saline for stent clearance of secretions is almost nonexistent. In fact, some research in this domain of the use of hypertonic saline has been established in cystic fibrosis related bronchiectasis. However hypertonic saline sometimes also does cause bronchospasm and airway narrowing (23). Other approaches for mucus and stent declogging included nebulization of $\mathrm{N}$-acetylcysteine, nebulization with bronchodilators and mucolytic containing cough syrup preparations. Other general precautions such as hydration is not a common approach among participants in this survey. İncentive spirometry was rarely mentioned as used to clear mucus plugging in the results of this survey.

Stent extraction is an integral subsequent part of the airway stenting procedures. Our study shows that the participants mostly combine rigid and flexible bronchoscopes for this. In Europe stent extraction (65\%) and placements $(73 \%)$ correlated well with use of RB only. Thus, you could infer maybe because stent placements in Europe are mostly with RB its extractions are also done similarly as personnel placing them may have easy access 
to $\mathrm{RB}$ resources. This could also be since in Europe silicon stents (47\%) were used mostly over SEMS (37\%). We did separately contact some of the respondents using FB only for stent extractions to understand their reasons for using it. Of the 19 respondents using FB only 7 responded back. Their main reasons for use of FB for stent extractions were lack of easy access to RB, general anesthesia and resources in the operating room. Lack of training for RB, and the opinion of having the experience before of safely extracting SEMS with FB were some of the other reasons as per email replies. The survey results however still suggested that rigid bronchoscope was the preferred device for removal of airway stents. The main reasons are safety of the airway, larger working channel which facilitates removal without harming the airway mucosal and submucosal layers. The removal of silicone stents absolutely requires $\mathrm{RB}$ and using rigid forceps to simultaneously twist-andpull the stent into the barrel of the rigid bronchoscope while maintaining continuous visual contact with the stent. Removing uncovered metallic stents in one piece is the most challenging procedure in airway stenting procedures. Covered metallic stents will have less tumor and granulation ingrowth, but still can cause mucosal injury and bleeding during removal attempt. After separating them from the airway wall, stents should be removed by rigid forceps. It can be said that RB is the compulsory device for safer procedural approach $(24,25)$. The rigid bronchoscope also facilitates a variety of techniques which can be applied for simple, moderately tough or complex removals $(25,26)$.

We acknowledge that we have multiple limitations in our limited questionnaire survey:

(I) An eight-question survey is clearly not enough to get all the attributes of such an extensive varied practice area of airway stenting from around the world. However, in web survey-based studies we do see a low response rate as the number of questions and time to complete increases resulting in incomplete responses, respondent fatigue attrition and dropout (27). Hence the authors focused questions more on the practice patterns and utility of airway stenting. Besides the country and their specialty of practice of the respondents we have no means to verify the age or duration of their practice in this field. So, it's clear there will be some reporting bias which is inevitably not excluded from the results of the survey. However, this is often a problem with most online surveybased studies.
(II) There could also be a limited selection bias in this survey as it was only sent to interventional pulmonary societies and some thoracic surgery communities around the world. It is very possible that there are more specialists who perform airway stenting. This includes our close working specialty of otolaryngologists and some interventional radiologists. There could have been an increased response rate to the survey by including these subspecialists also in this study.

(III) Also, some of the continents in the survey (SA, Africa, Australia) have a low rate of respondents despite multiple attempts to get responses from members there. This could very well result in sampling and participation bias involving results from those continents. Thus, the data from these continents may not clearly reflect the practices and preferences of airway stenting in those regions.

(IV) One of the questions on the removal of stents was added unfortunately 3 weeks after the survey was started. Thus, we only have 147 responses for this question. With a much higher response rate on this, it would probably have given us deeper insight into practices on the extraction of stents. However, if this question was excluded the real attrition rate for our survey for the rest of the study was very low about $3 \%$.

\section{Conclusions}

Tracheobronchial stent deployment and maintenance practices vary much around the world. The use of stent material and deployment resources is much dependent on available local expertise of the professional placing it. It has variations around the world since training and standardizations are clearly not defined. Stent engineering, designing and innovations in its deployment is a very slow steady evolving process. However, innovations in the field are slow to penetrate around the world with limited studies under its domain.

\section{Acknowledgments}

Funding: None.

\section{Footnote}

Reporting Checklist: The authors have completed the 
STROBE reporting checklist. Available at http://dx.doi. org/10.21037/jtd-20-2080

Data Sharing Statement: Available at http://dx.doi. org/10.21037/jtd-20-2080

Conflicts of Interest: All authors have completed the ICMJE uniform disclosure form (available at http://dx.doi. org/10.21037/jtd-20-2080). The authors have no conflicts of interest to declare.

Ethical Statement: The authors are accountable for all aspects of the work in ensuring that questions related to the accuracy or integrity of any part of the work are appropriately investigated and resolved. Answering the survey was considered to be consent to be included in the study. Patients were not involved in this study.

Open Access Statement: This is an Open Access article distributed in accordance with the Creative Commons Attribution-NonCommercial-NoDerivs 4.0 International License (CC BY-NC-ND 4.0), which permits the noncommercial replication and distribution of the article with the strict proviso that no changes or edits are made and the original work is properly cited (including links to both the formal publication through the relevant DOI and the license). See: https://creativecommons.org/licenses/by-nc-nd/4.0/.

\section{References}

1. Dutau H, Dumon JF. Airway Stenting Revisited: 30 Years, the Age of Reason? J Bronchology Interv Pulmonol 2017;24:257-9.

2. Dutau H, Breen D, Bugalho A, et al. Current Practice of Airway Stenting in the Adult Population in Europe: A Survey of the European Association of Bronchology and Interventional Pulmonology (EABIP). Respiration 2018;95:44-54.

3. Facciolongo N, Piro R, Menzella F, et al. Training and practice in bronchoscopy a national survey in Italy. Monaldi Arch Chest Dis 2013;79:128-33.

4. Sethi S, Gildea TR, Almeida FA, et al. Clinical Success Stenting Distal Bronchi for "Lobar Salvage" in Bronchial Stenosis. J Bronchology Interv Pulmonol 2018;25:9-16.

5. Fruchter O, Abed El Raouf B, Rosengarten D, et al. Longterm Outcome of Short Metallic Stents for Lobar Airway Stenosis. J Bronchology Interv Pulmonol 2017;24:211-5.

6. Young BP, Machuzak MS, Gildea RT Initial Clinical
Experience Using 3D Printing and Patient-Specific Airway Stents: Compassionate Use of 3D Printed PatientSpecific Airway Stents. Am J Respir Crit Care Med 2020;201:A1711.

7. Dutau H, Maldonado F, Laroumagne S, et al. Silicone stents, the rigid bronchoscope, and the standard of care in central airway stenosis. Curr Respir Care Rep 2012;1:46-53.

8. Herth F, Becker HD, LoCicero J 3rd, et al. Successful bronchoscopic placement of tracheobronchial stents without fluoroscopy. Chest 2001;119:1910-2.

9. Miyazawa T, Miyazu Y, Iwamoto Y, et al. Stenting at the flow-limiting segment in tracheobronchial stenosis due to lung cancer. Am J Respir Crit Care Med 2004;169:1096-102.

10. Hayashi A, Takanashi S, Tsushima T, et al. New method for quantitative assessment of airway calibre using a stereovision fiberoptic bronchoscope. Br J Anaesth 2012;108:512-6.

11. Nobuyama S, Sato T, Handa H, et al. Comparison of Airway Measurements for Tracheobronchial Stenosis Between Stereoscopic Bronchoscope and MD-CT. J Bronchology Interv Pulmonol 2017;24:296-302.

12. Begnaud A, Connett JE, Harwood EM, et al. Measuring central airway obstruction. What do bronchoscopists do? Ann Am Thorac Soc 2015;12:85-90.

13. Chung FT, Chen HC, Chou CL, et al. An outcome analysis of self-expandable metallic stents in central airway obstruction: a cohort study. J Cardiothorac Surg 2011;6:46.

14. Breen DP, Dutau H. On-site customization of silicone stents: towards optimal palliation of complex airway conditions. Respiration 2009;77:447-53.

15. Anupam K, Hanine I, Satish K, et al. Silicone Stent Customization for Complex Airway Disorders - A Single Center Experience. Chest 2015;148:847A.

16. Guibert N, Didier A, Moreno B, et al. Treatment of Post-transplant Complex Airway Stenosis with a ThreeDimensional, Computer-assisted Customized Airway Stent. Am J Respir Crit Care Med 2017;195:e31-3.

17. Cheng GZ, Folch E, Wilson A, et al. 3D Printing and Personalized Airway Stents. Pulm Ther 2017;3:59-66.

18. Freitag L, Gördes M, Zarogoulidis P, et al. Towards Individualized Tracheobronchial Stents: Technical, Practical and Legal Considerations. Respiration 2017;94:442-56.

19. Fuehner T, Suhling H, Greer $M$, et al. Biodegradable stents after lung transplantation. Transpl Int 2013;26:e58-60.

20. Ayub A, Al-Ayoubi AM, Bhora FY. Stents for airway strictures: selection and results. J Thorac Dis 2017;9:S116-21.

21. Dutau H, Musani A, I, Laroumagne S, et al. Biodegradable 
Airway Stents - Bench to Bedside: A Comprehensive Review. Respiration 2015;90:512-21.

22. Folch E, Keyes C. Airway stents. Ann Cardiothorac Surg 2018;7:273-83.

23. Elkins MR, Bye PT. Mechanisms and applications of hypertonic saline. J R Soc Med 2011;104 Suppl 1:S2-5.

24. Madan K, Agarwal R, Aggarwal AN, et al. Therapeutic rigid bronchoscopy at a tertiary care center in North India: Initial experience and systematic review of Indian literature. Lung India 2014;31:9-15.

Cite this article as: Mathew R, Hibare K, Dalar L, Roy WE. Tracheobronchial stent sizing and deployment practices airway stenting practices around the world: a survey study. J Thorac Dis 2020;12(10):5495-5504. doi: 10.21037/jtd-20-2080
25. Innabi A, Mcclelland S, Raman T, et al. No stent left behind: A Review of Stent removal and related complications. EMJ Respir 2017;5:78-84.

26. Murgu S, Stoy S. The When, the How and the Why of Metallic Stent Removal. J Bronchology Interv Pulmonol 2016;23:266-71.

27. Hochheimer CJ, Sabo RT, Krist AH, et al. Methods for Evaluating Respondent Attrition in Web-Based Surveys. J Med Internet Res 2016;18:e301. 
Table S1 Which country do you work or practice? Breakdown of responses from continents as below

\begin{tabular}{|c|c|c|}
\hline $\begin{array}{l}\text { Continents (No. of countries } \\
\text { responded) }(n=47)\end{array}$ & $\%$ & $\begin{array}{l}\text { Number of responses } \\
\qquad(\mathrm{n}=269)\end{array}$ \\
\hline N. America [3] & & 72 \\
\hline Canada & 1.86 & 5 \\
\hline Costa Rica & 0.37 & 1 \\
\hline USA & 24.54 & 66 \\
\hline S. America [4] & & 7 \\
\hline Argentina & 1.12 & 3 \\
\hline Brazil & 0.37 & 1 \\
\hline Chile & 0.74 & 2 \\
\hline Ecuador & 0.37 & 1 \\
\hline Europe [22] & & 97 \\
\hline Austria & 0.74 & 2 \\
\hline Belgium & 1.12 & 3 \\
\hline Bulgaria & 0.74 & 2 \\
\hline Cyprus & 0.37 & 1 \\
\hline Denmark & 0.74 & 2 \\
\hline Estonia & 0.37 & 1 \\
\hline Finland & 0.37 & 1 \\
\hline France & 2.60 & 7 \\
\hline Germany & 2.60 & 7 \\
\hline Greece & 1.86 & 5 \\
\hline Ireland & 0.37 & 1 \\
\hline Italy & 8.18 & 22 \\
\hline Netherlands & 1.12 & 3 \\
\hline Portugal & 1.86 & 5 \\
\hline Romania & 0.74 & 2 \\
\hline Serbia & 0.74 & 2 \\
\hline Spain & 1.49 & 4 \\
\hline Sweden & 0.74 & 2 \\
\hline Switzerland & 1.12 & 3 \\
\hline Turkey & 6.69 & 18 \\
\hline UK \& N Ireland & 1.12 & 3 \\
\hline Poland & 0.37 & 1 \\
\hline Africa [3] & & 7 \\
\hline South Africa & 1.49 & 4 \\
\hline Egypt & 0.74 & 2 \\
\hline Sudan & 0.37 & 1 \\
\hline Asia [14] & & 78 \\
\hline China & 1.49 & 4 \\
\hline India & 16.36 & 44 \\
\hline Indonesia & 0.74 & 2 \\
\hline Iran & 1.86 & 5 \\
\hline Israel & 0.74 & 2 \\
\hline Japan & 0.74 & 2 \\
\hline Malaysia & 2.60 & 7 \\
\hline Nepal & 0.74 & 2 \\
\hline Philippines & 0.74 & 2 \\
\hline Republic of Korea & 0.37 & 1 \\
\hline Singapore & 1.12 & 3 \\
\hline Thailand & 0.74 & 2 \\
\hline United Arab Emirates & 0.37 & 1 \\
\hline Saudi Arabia & 0.37 & 1 \\
\hline Australia [1] & & 8 \\
\hline Australia & 2.97 & 8 \\
\hline
\end{tabular}

Table S2 Breakdown of other miscellaneous methods for sizing of stents

\begin{tabular}{lcc}
\hline Methods & $\%$ & $\mathrm{~N}=19$ \\
\hline Radial EBUS & $0.7 \%$ & 2 \\
Rigid bronchoscope size & $1.5 \%$ & 4 \\
Serial balloon dilation size & $3.7 \%$ & 10 \\
Stereo bronchoscope & $0.4 \%$ & 1 \\
Rigid forceps size & $0.7 \%$ & 2 \\
\hline EBUS, endobronchial ultrasound. & &
\end{tabular}


Table S3 Breakdown by continents of the methods used for sizing of stents

\begin{tabular}{|c|c|c|c|c|c|c|}
\hline Methods for sizing \% [n] & N. America & S. America & Europe & Africa & Asia & Australia \\
\hline Tracheal and bronchial stent sizing devices & $17[13]$ & - & $11[12]$ & - & 4 [3] & $50[4]$ \\
\hline $\begin{array}{l}\text { Measurement with bronchoscope and ruler } \\
\text { during the procedure }\end{array}$ & 69 [51] & $28[2]$ & $60[59]$ & $43[3]$ & 69 [55] & $75[7]$ \\
\hline Others & $13[11]$ & $14[1]$ & $4[4]$ & & $4[3]$ & - \\
\hline
\end{tabular}

Table S4 Breakdown table by continents on modality of placement and removal of tracheobronchial stents (TBS)

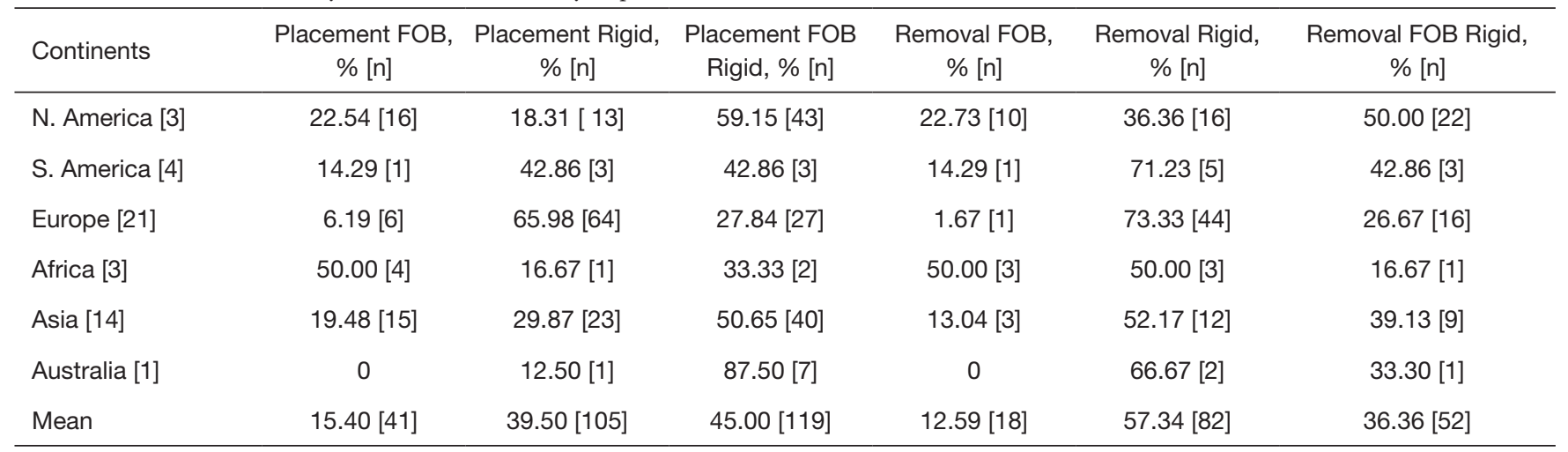

Placement TBS $P$ value $<0.00001$; removal TBS $P$ value $<0.00001$. FOB, fiberoptic bronchoscopy.

Table S5 Breakdown table by continents on use of fluoroscopy and biodegradable stents

\begin{tabular}{|c|c|c|c|c|c|}
\hline Continents & $\begin{array}{c}\text { Fluoroscopy: yes, } \\
\qquad \%[n]\end{array}$ & $\begin{array}{l}\text { Fluoroscopy: no, } \\
\qquad \%[n]\end{array}$ & $\begin{array}{c}\text { Some fluoroscopy, } \\
\%[\mathrm{n}]\end{array}$ & $\begin{array}{l}\text { Biodegr stents: yes, } \\
\quad \%[n]\end{array}$ & $\begin{array}{c}\text { Biodegr stents: no, } \\
\%[\mathrm{n}]\end{array}$ \\
\hline N. America [3] & 25.00 [18] & 51.59 [37] & $23.61[17]$ & 0 & $100.00[72]$ \\
\hline Europe [21] & $15.46[15]$ & 55.67 [53] & 28.87 [28] & $14.58[14]$ & 85.42 [82] \\
\hline Africa [3] & $50.00[3]$ & 33.33 [2] & $16.67[1]$ & 0 & $100.00[7]$ \\
\hline Australia [1] & 25.00 [2] & $12.50[1]$ & $62.50[5]$ & $12.50[1]$ & $87.50[7]$ \\
\hline Mean & 22.85 [61] & $50.94[136]$ & 26.22 [70] & 7.49 [20] & 92.51 [247] \\
\hline
\end{tabular}

Fluoroscopy use for TBS P value $<0.00001$; not using Biodegr stent $\mathrm{P}$ value $<0.00001$. TBS, tracheobronchial stents; Biodegr, biodegradable stents. 


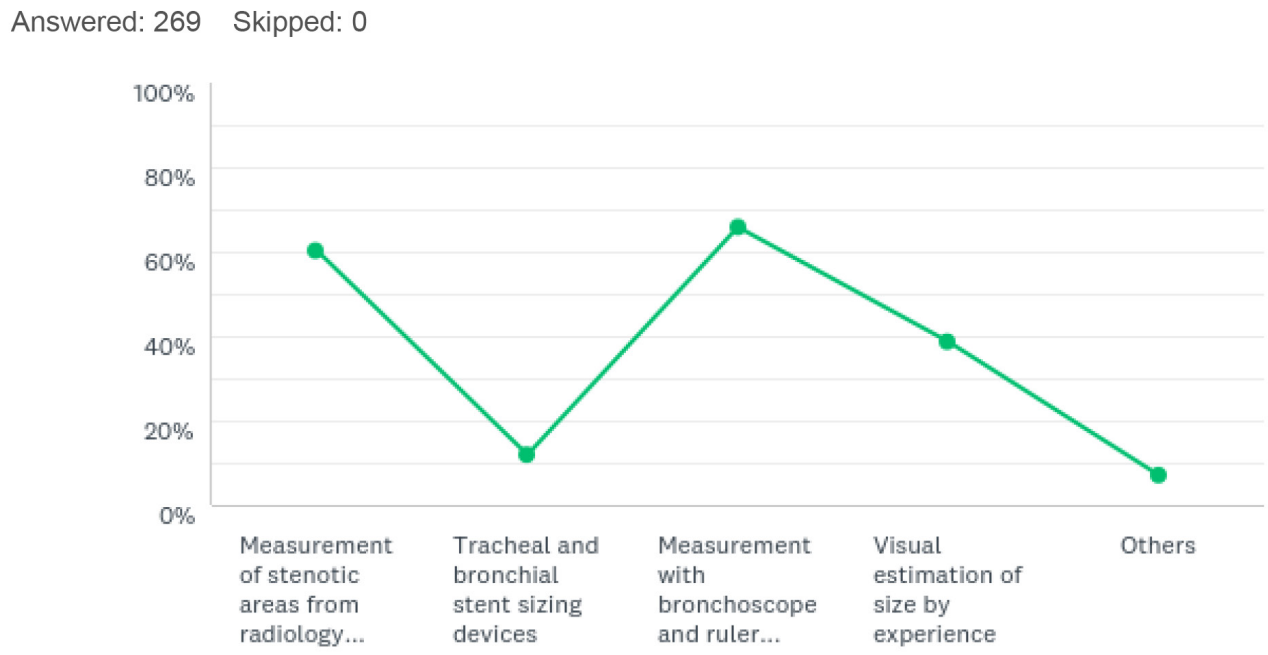

\begin{tabular}{|c|c|c|}
\hline ANSWER CHOICES & RESPON & ES \\
\hline Measurement of stenotic areas from radiology images & $60.22 \%$ & 162 \\
\hline Tracheal and bronchial stent sizing devices & $11.90 \%$ & 32 \\
\hline Measurement with bronchoscope and ruler during the procedure & $65.80 \%$ & 177 \\
\hline Visual estimation of size by experience & $38.66 \%$ & 104 \\
\hline Others & $7.06 \%$ & 19 \\
\hline
\end{tabular}

Figure S1 How do you size your tracheal and bronchial stents? 


\section{How do you size your tracheal and bronchial stents?}

100

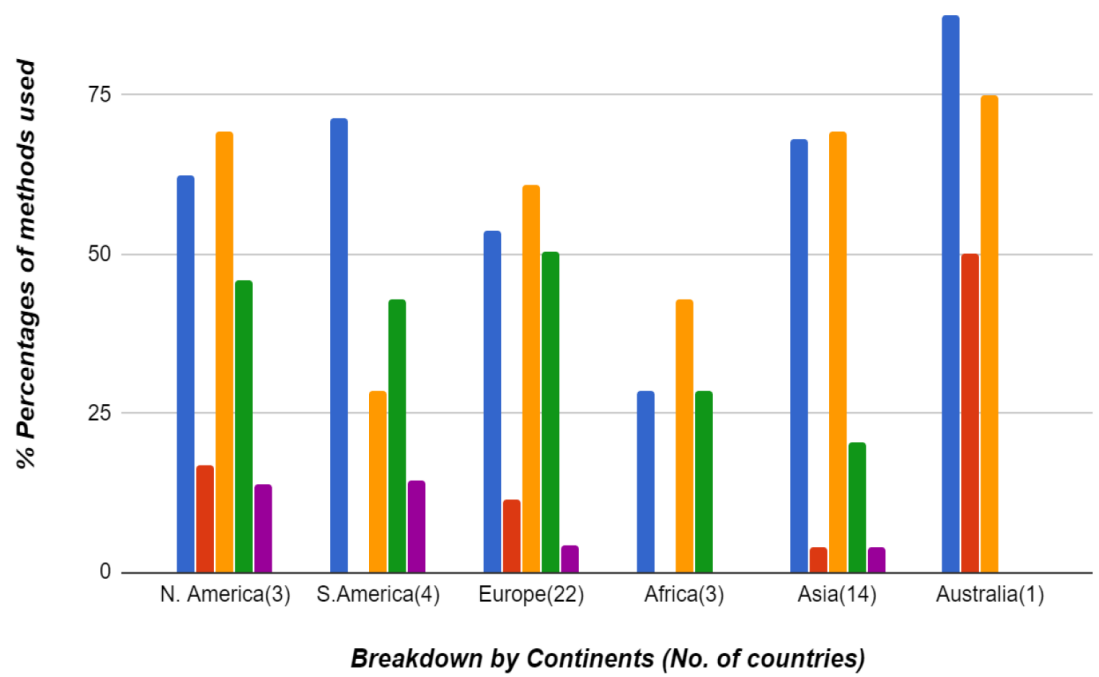

Figure S2 How do your size your tracheal and bronchial stents? Breakdown by continents.
Measurement of stenotic areas from radiology images

Tracheal and bronchial stent sizing devices

Measurement with bronchoscope and ruler during the procedure

Visual estimation of size by experience

Other methods

S2 How do your size your trachel and bronch shent Breakdown by continents. 
Answered: 266 Skipped: 3

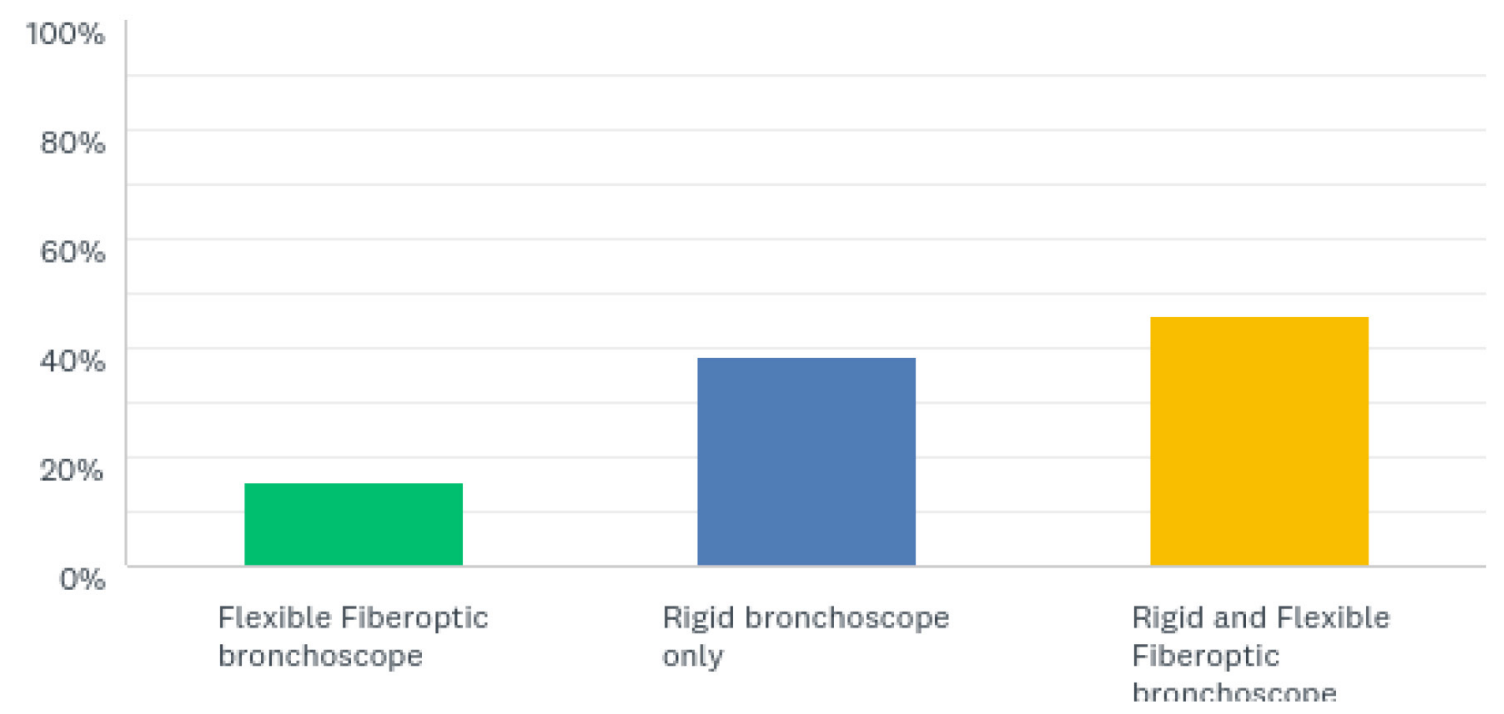

\section{ANSWER CHOICES}

\section{RESPONSES}

Flexible Fiberoptic bronchoscope

$15.41 \%$

Rigid bronchoscope only

$38.35 \%$

102

Rigid and Flexible Fiberoptic bronchoscope

$46.24 \%$

TOTAL

Figure S3 How do you place your tracheobronchial stents most of the time? 
Answered: 267 Skipped: 2

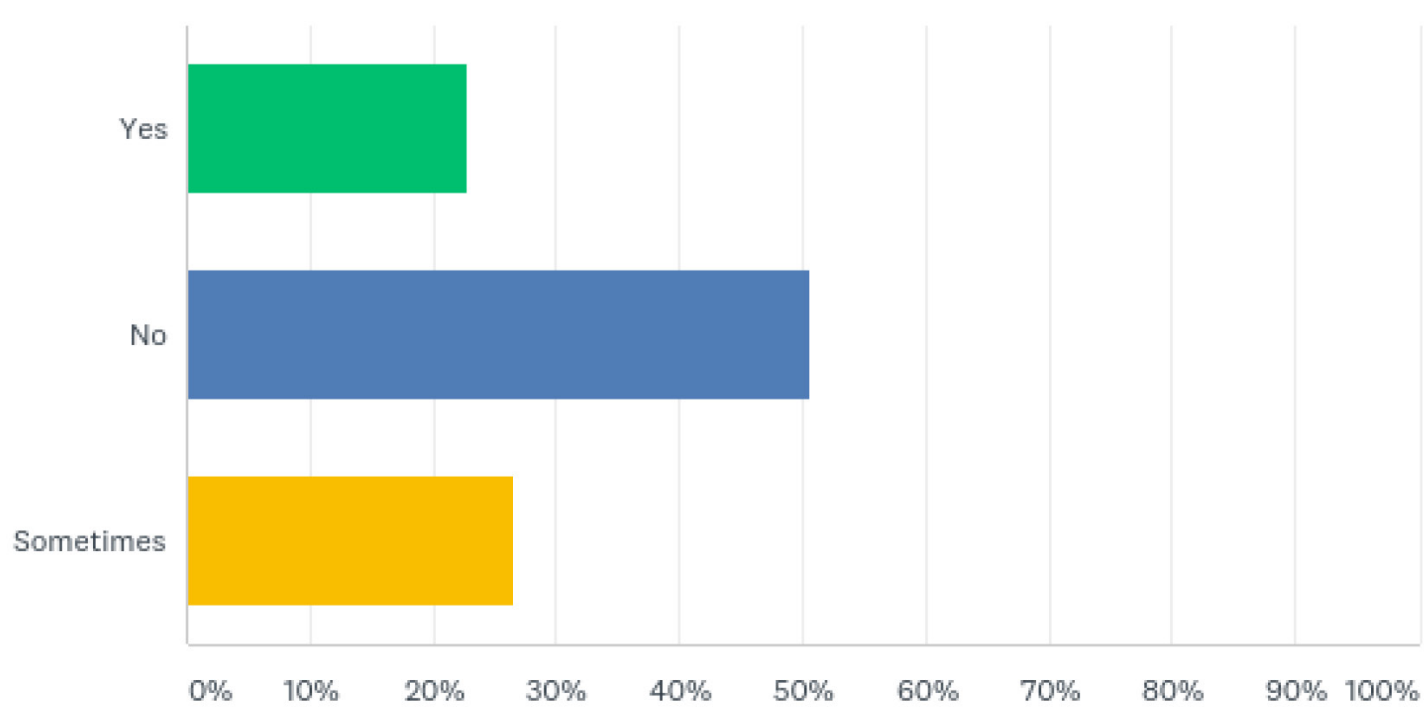

\begin{tabular}{l|l} 
ANSWER CHOICES & RESPONSES
\end{tabular}

\begin{tabular}{lcr} 
Yes & $22.85 \%$ & 61 \\
\hline No & $50.56 \%$ & 135 \\
\hline Sometimes & $26.59 \%$ & 71 \\
TOTAL & & 267
\end{tabular}

Figure S4 Do you always use fluoroscopy guidance for placement of your airway stents? 


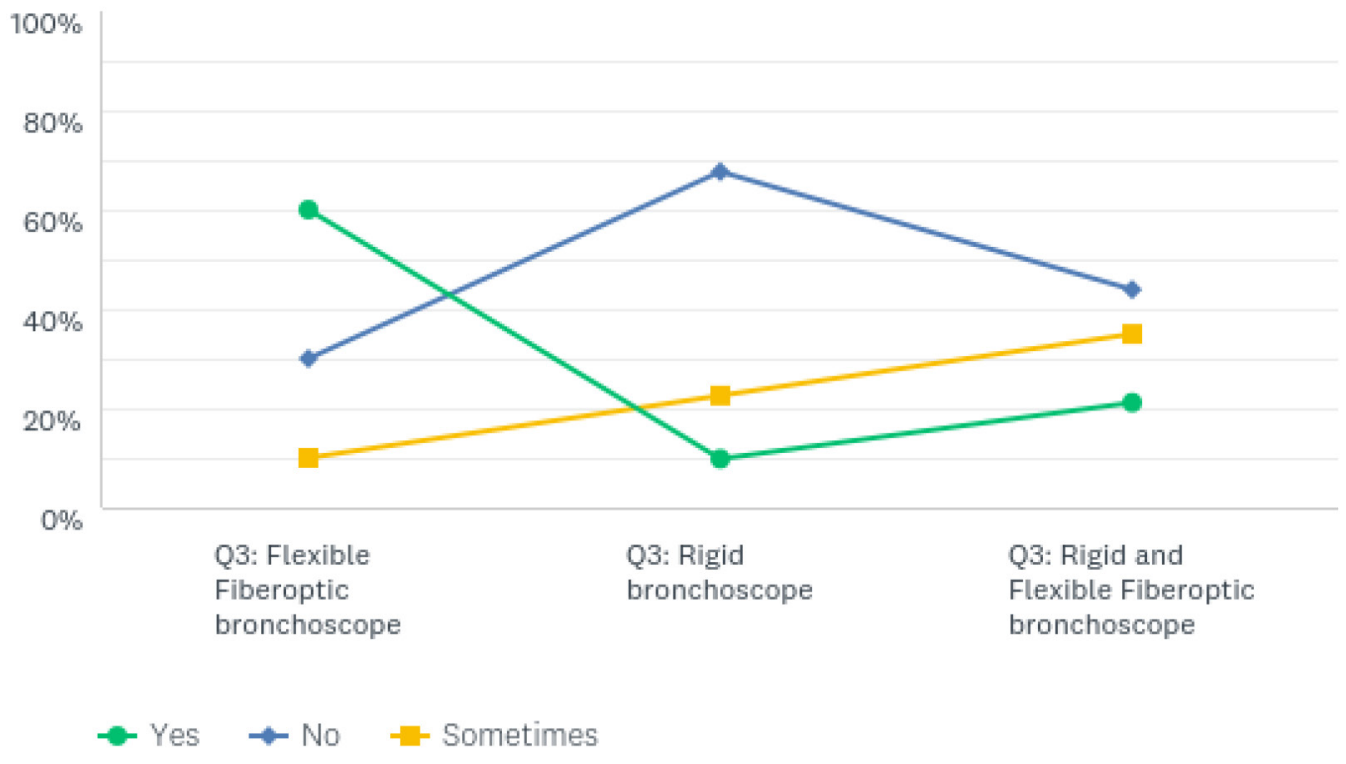

\begin{tabular}{|c|c|c|c|}
\hline & YES & No & SOMETIMES \\
\hline Q3: Flexible Fiberoptic bronchoscope & $\begin{array}{r}60.00 \% \\
24\end{array}$ & $\begin{array}{r}30.00 \% \\
12\end{array}$ & $\begin{array}{r}10.00 \% \\
4\end{array}$ \\
\hline Q3: Rigid bronchoscope & $\begin{array}{r}9.80 \% \\
10\end{array}$ & $\begin{array}{r}67.65 \% \\
69\end{array}$ & $\begin{array}{r}22.55 \% \\
23\end{array}$ \\
\hline $\begin{array}{l}\text { Q3: Rigid and Flexible Fiberoptic } \\
\text { bronchoscope }\end{array}$ & $\begin{array}{r}21.14 \% \\
26\end{array}$ & $\begin{array}{r}43.90 \% \\
54\end{array}$ & $\begin{array}{r}34.96 \% \\
43\end{array}$ \\
\hline Total Respondents & 60 & 135 & 70 \\
\hline
\end{tabular}

Figure S5 Breakdown of fluoroscopy use when placing stents with rigid or flexible bronchoscopy or both. 
Answered: 267 Skipped: 2

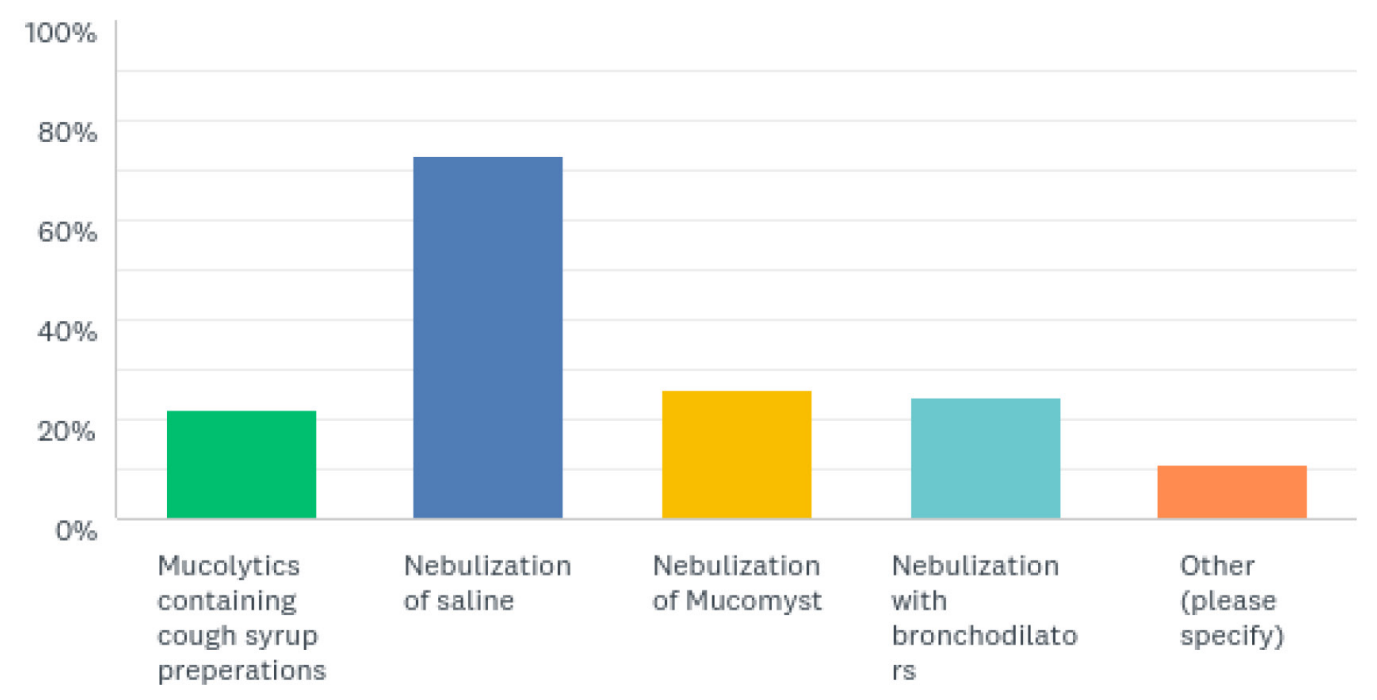

\begin{tabular}{|c|c|c|}
\hline ANSWER CHOICES & RESPON & \\
\hline Mucolytics containing cough syrup preperations & $22.10 \%$ & 59 \\
\hline Nebulization of saline & $73.03 \%$ & 195 \\
\hline Nebulization of Mucomyst & $26.22 \%$ & 70 \\
\hline Nebulization with bronchodilators & $24.34 \%$ & 65 \\
\hline Other (please specify) & $11.24 \%$ & 30 \\
\hline
\end{tabular}

Figure S6 What do you advise your patients to prevent mucus clogging of their stents? 


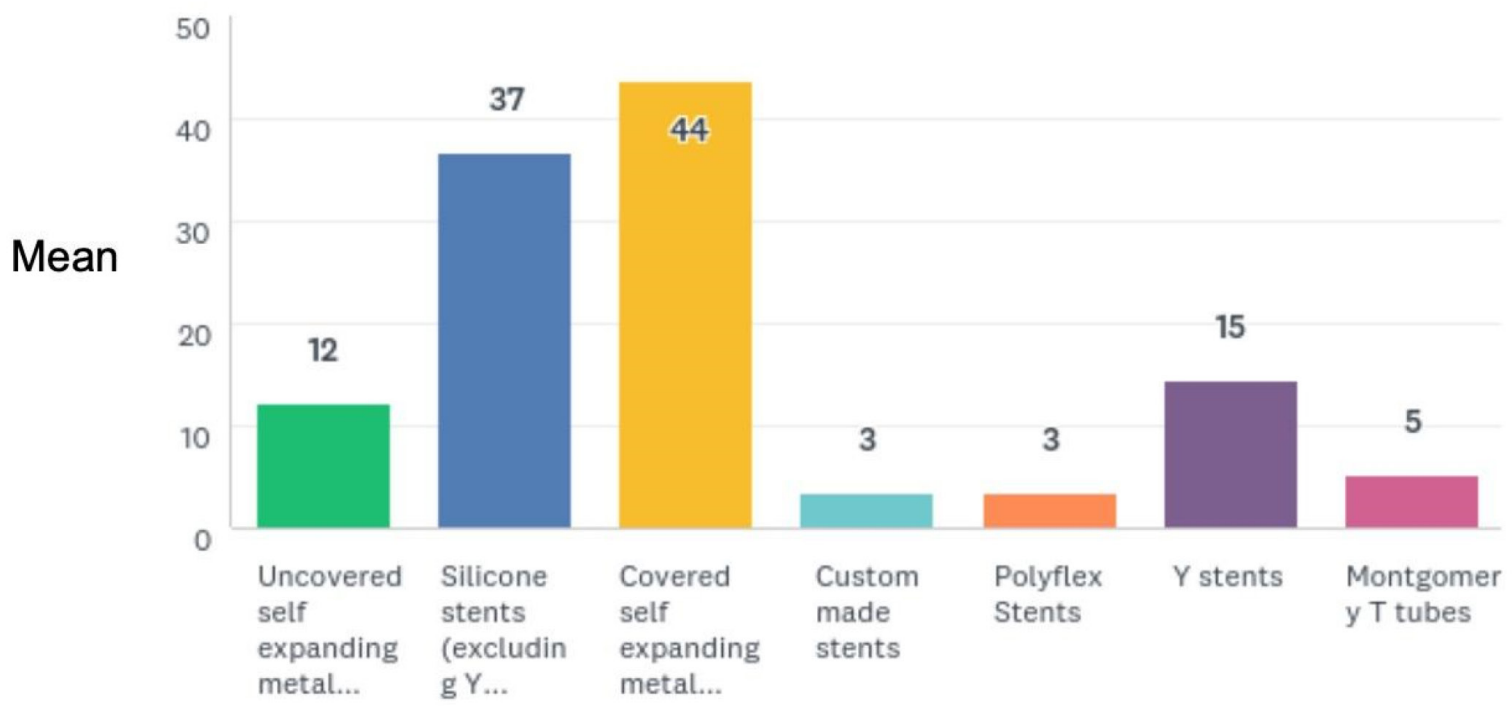

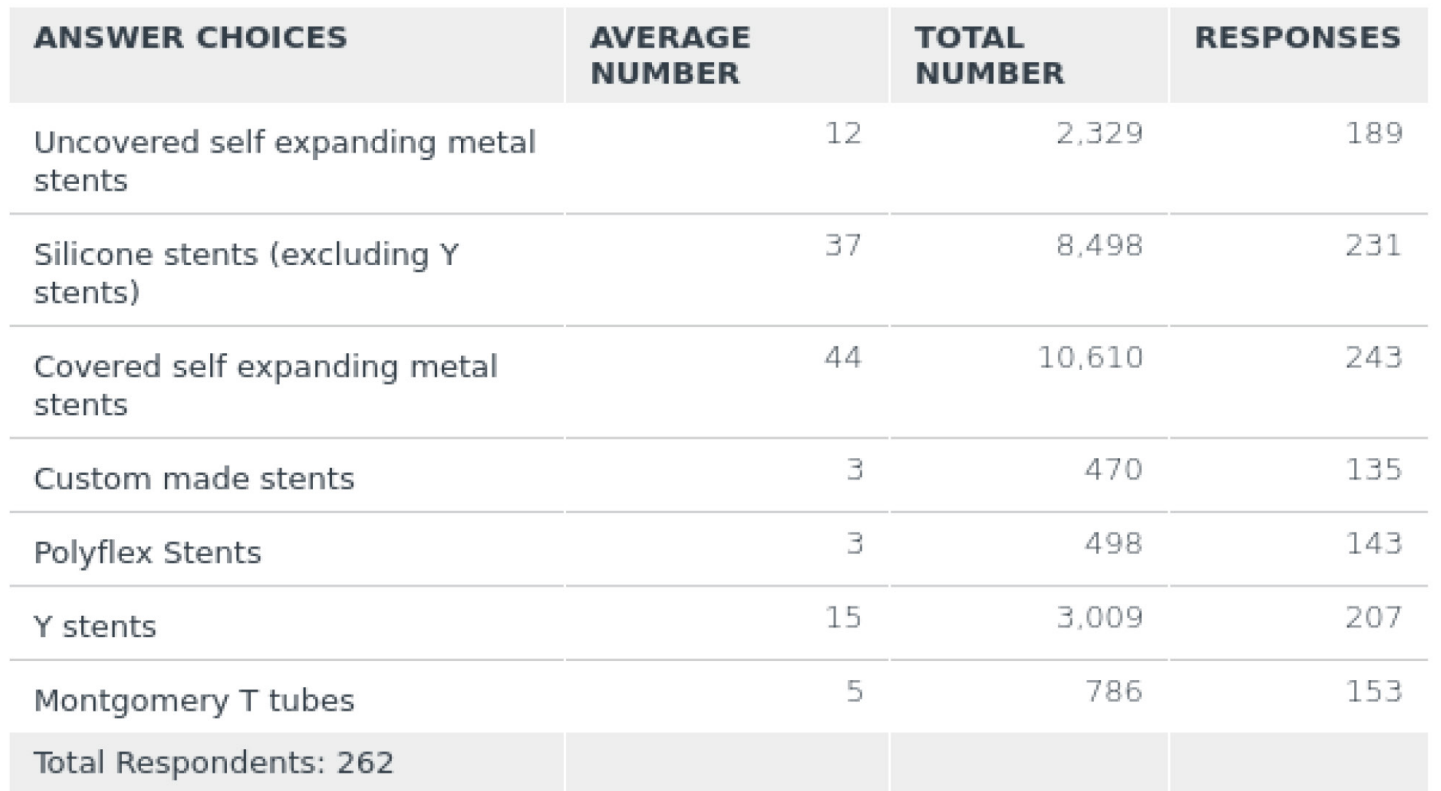

Figure S7 What is approximately the percentages for the type of tracheobronchial stents that you use in your practice? 


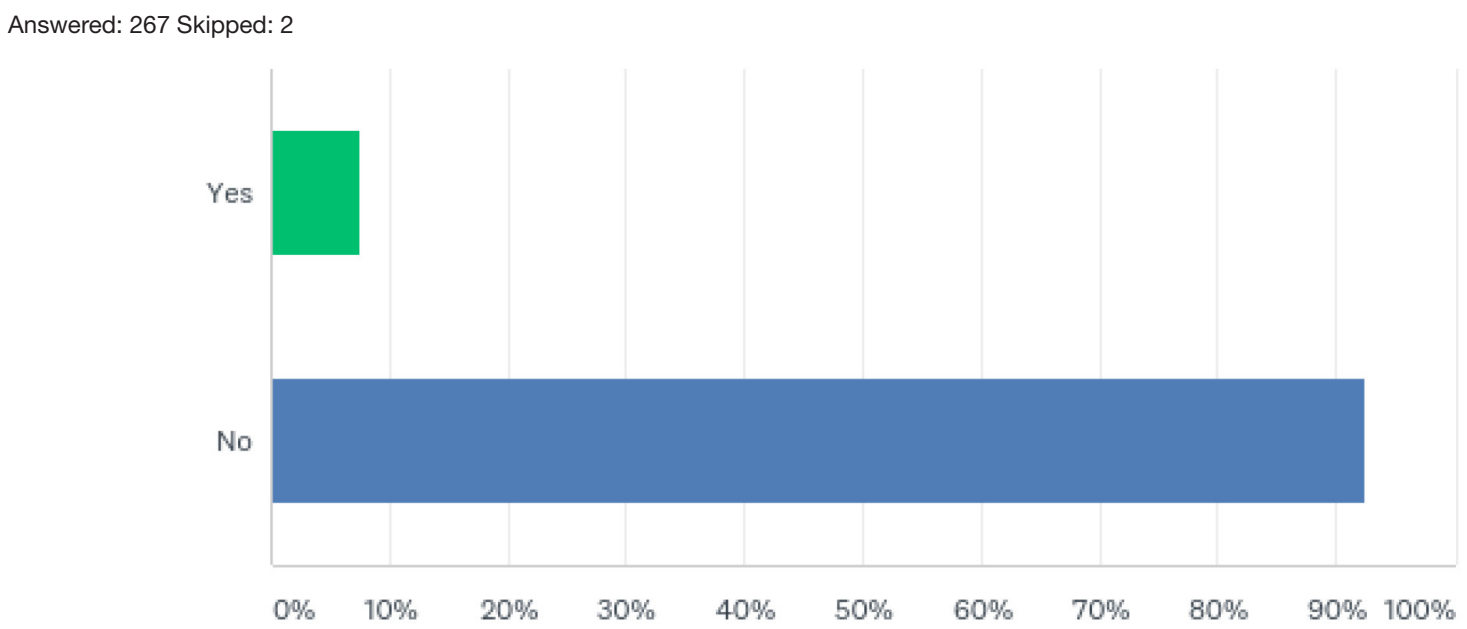

\begin{tabular}{llr} 
ANSWER CHOICES & RESPONSES & \\
\hline YeS & $7.49 \%$ & 20 \\
\hline No & $92.51 \%$ & 247 \\
\hline TOTAL & & 267
\end{tabular}

Figure S8 Do you have any experience with the use of biodegradable stents? If so, what cases have you used it for? 


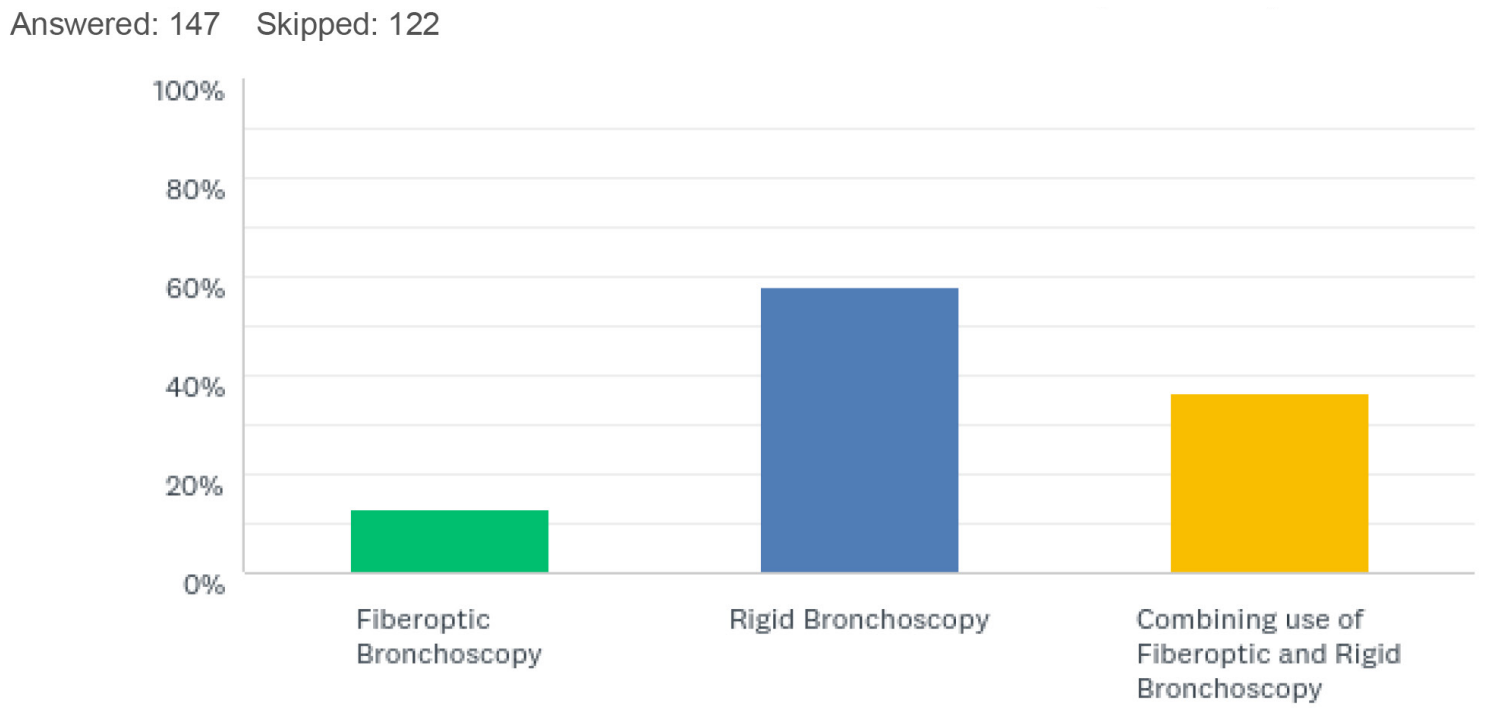

\section{ANSWER CHOICES}

RESPONSES

Fiberoptic Bronchoscopy

$12.93 \%$

Rigid Bronchoscopy

$57.82 \%$

85

Combining use of Fiberoptic and Rigid Bronchoscopy

$36.73 \%$ 54

Total Respondents: 147

Figure S9 How do you remove or extract tracheobronchial stents that you have placed? 